\title{
The Effects of Secondary Hyperparathyroidism on Circadian Blood Pressure in Hemodialysis Patients
}

\author{
Burkay Yakar ${ }^{1}$, Erhan Onalan², Edibe Pirincci ${ }^{3}$, Mehmet Onur Kaya ${ }^{4}$ and Mustafa Demir ${ }^{5}$ \\ ${ }^{1}$ Department of Family Medicine, Firat University, Elazig, Turkey \\ ${ }^{2}$ Department of Internal Medicine, Firat University, Elazig, Turkey \\ ${ }^{3}$ Department of Public Health, Firat University, Elazig, Turkey \\ ${ }^{4}$ Department of Biostatistics and Medical Informatics, Firat University, Elazig, Turkey \\ ${ }^{5}$ Department of Internal Medicine, Division of Nephrology, Tokat City Hospital, Tokat,Turkey
}

\begin{abstract}
Objective: To determine the relationship between secondary hyperparathyroidism (sHPT) and circadian blood pressure (BP) rthym among patients undergoing hemodialysis treatment.

Study Design: A descriptive and prospective cohort study.

Place and Duration of Study: Department of Nephrology, Firat University Hospital, Turkey, between June and December 2019.

Methodology: Eighty-five patients, undergoing hemodialysis three times a week, were included. The BP parameters and circadian blood pressure rhythm were measured by the mobil-o-graph sphygmomanometer. Non-dipper blood pressure phenomenon was defined as a night-time mean artery pressure (MAP) decrease of $<10 \%$ from the daytime MAP; sHPT was defined as parathormone $>300 \mathrm{pg} / \mathrm{ml}$.

Results: Of the 85 participants, mean age was $57.07 \pm 14.46$ years. In cohort, sHPT rate $58.8 \%(n=50)$ and non-dipper blood pressure pattern rate was $64.7 \%(n=55)$. Systolic blood pressure $(p=0.001)$, diastolic blood pressure $(p=0.001)$, and mean arterial blood pressure $(p<0.001)$ were higher in participants with sHPT. SHPT $(p=0.003)$ was an independent risk factor for non-dipper blood pressure pattern (odds ratio [OR] $0.065,95 \% \mathrm{Cl}: 0.11-0.390$ ). A negative correlation was identified between parathormone and the reduction in night blood pressure $(r=-0.346, p=0.001)$.

Conclusion: Secondary hyperparathyroidism can cause non-dipper blood pressure pattern by reducing the reduction in night blood pressure. Treatment of sHPT is important in the control of blood pressure and normal circadian blood pressure rhythm in tertiary protection in hemodialysis patients.
\end{abstract}

Key Words: Blood pressure, Circadian rhythm, Hyperparathyroidism secondary, Hemodialysis, Chronic kidney diseases.

How to cite this article: Yakar B, Onalan E, Pirincci E, Kaya MO, Demir M. The Effects of Secondary Hyperparathyroidism on Circadian Blood Pressure in Hemodialysis Patients. J Coll Physicians Surg Pak 2021; 31(11):1325-1330.

\section{INTRODUCTION}

Ambulatory blood pressure monitoring (ABPM) has been increasingly used in clinical management of hypertension. The 24-hour blood pressure (BP) pattern is more predictive of cardiovascular event risk than routine office BP. ${ }^{1}$ Previous studies reported that average nighttime sleep BPs are generally better predictors of adverse cardiovascular outcomes than average daytime awake BPs levels. Ambulatory blood pressure is also important in detecting the non-dipper blood pressure phenomenon. Night-time blood pressure is reduced by $10-20 \%$ in healthy individuals with circadian blood pressure.

Correspondence to: Dr. Burkay Yakar, Department of

Family Medicine, Firat University, Elazig, Turkey

E-mail: byakar@firat.edu.tr

Received: July 26, 2021; Revised: September 15, 2021;

Accepted: October 04, 2021

DOI: https://doi.org/10.29271/jcpsp.2021.11.1325
People with a fall of less than $10 \%$ are called non-dipper blood pressure phenomenon. ${ }^{2-4}$ A meta-analysis study showed that non-dipper and reverse dipper phenomenon are asociated with worse cardiovascular events and elevated night-day BP ratio is significantly and independently predict mortality in hypertensive patients. $^{5}$

Chronic kidney disease (CKD) is an another important risk factor forcardiovascular events. Traditional riskfactors, suchas hypertension [HT], diabetes mellitus [DM], age, gender, smoking, and dislipidemia; and non-traditional risk factors, such as left ventricular hypertrophy, serum albumin, hemoglobin, phosphate, and urate levels are responsible for cardiovasculer events in CKD. ${ }^{6}$ Recently, it has been emphasised that the nondipper phenomenon that occurs in chronic renal failure may be an important cardiovascular risk factor. Previous studies reported that non-dipper phenomenon incidence is $41 \%$ among patients with chronic renal failure and higher than hypertensive patients without CKD. ${ }^{7}$ Previous studies focused on treatment of 
non-dipper fenomen and those studies reported that evening drug therapy significant decreases in nocturnal systolic and diastolic blood pressure. In literature, there is no sufficiant data to explain higher non-dipper phenomenon incidence among patients with CKD. ${ }^{2,8,9}$

A limited number of studies in the literature have claimed that hyperparathyroidism may be associated with increased BP and non-dipper phenomenon. The condition of SHPT, which is common in hemodialysis patients, is known to be associated with poor quality of life. It also directly increases the risk of cardiovascular events due to valvular and vascular calcification, and may be another cardiovascular risk factor in association with increased blood pressure and non-dipper phenomenon. ${ }^{7,10}$ A previous study reported that parathyroidectomy led to a reduction in blood pressure. Another study reported that the prevalence of metabolic syndrome, elevated BP, and nondipping phenomenon significantly decreased after parathyroidectomy. ${ }^{11}$ Secondary hyperparathyroidism is associated with high cardiovascular morbidity, but the relation between sHPT and circadian blood pressure is still controversial. There is no study in the literature to explain the relationship between sHPT and circadian blood pressure rhythm.

The current study focused on the association between sHPT and the non-dipper phenomenon, which is common in hemodialysis patients. The study data may contribute to the reduction of the non-dipper phenomenon incidence and increased cardiovascular risk among hemodialysis patients. The current study was aimed to investigate the relationship between SHPT and circadian blood pressure rhythm in a population undergoing hemodialysistreatment.

\section{METHODOLOGY}

This descriptive and prospective cohort study was performed at Hemodialysis Unit, Department of Nephrology, Firat University Hospital, between June and December 2019. Patients were included if they were 18 years or older, had undergoing hemodialysis treatment at least one year for three times a week for end-stage renal diseases. Exclusion criteria were determined as being younger than 18 years of age, having physical and mental disability for 24-hour ambulatory blood pressure measurement, having high parathormone levels other than sHPT due to CKD, having sleep disorders, and not being willing to participate in the study. One hundred patients were followed up in the Hemodialysis Unit for hemodialysis treatment. All under-treatment hemodialysis patients constituted the population of the study. Eighty-five patients, who met the study criteria and could adapt to ABPM, were included in the study (response rate $=85 \%$ ). The adequeacy of the sample size was checked with the posthoc power analysis since the study was a new and unique in the literature. For this, posthoc power analysis was performed for the blood pressure variable with the largest extent of dispersion used in the study. For the relevant variable, it was determined that 0.92 power was reached with the power analysis performed between the two indepeendent groups at the two independent groups at the 0.77 effect size $(d)$ and 0.05 significance level and the effect size was sufficient. Written and verbal consents of all participants were obtained.

The biochemical parameters of the patients were obtained from the hospital database. The socio-demographic characteristics of the participants were obtained with the questionnaire form prepared by review of the literature. Their demographic characteristics, which included age, gender, marital status, educational level, comorbid diseases (HT, DM), smoking habits, duration of HT and hemodialysis were questioned. Standing height of patients were measured with $0.1 \mathrm{~cm}$ sensitive linear height scale. The dry weight of the patients were measured with sensitive digital scale. Body mass index (BMI) was calculated using the conventional Queteletformula $\left(\mathrm{BMI}=\mathrm{Kg} / \mathrm{m}^{2}\right)$.

For each 24 hours measurement, overall, night-time and day-time mean systolic blood pressure (SBP) and diastolic blood pressure (DBP) values were recorded, and mean artery pressure (MAP) for day-time and night-time was calculated by the formula: $[M A P=D B P+(S B P-D B P) / 3]$. Non-dipper blood pressure phenomenon was defined as a night-time MAP decrease of $<10 \%$ from the daytime MAP. ${ }^{2,3}$ For each measurement, the rate of changes between the daytime and night-time blood pressures at the same time was calculated using the formula: [ (night SKB-daytime SKB)/daytime SKB]*100.

Assessment of SHPT in maintenance dialysis populations was through reports of parathyroid hormone (PTH) concentration. Based on the $2002 \mathrm{KDOQI}$ clinical practice guidelines, SHPT was defined as PTH $>300 \mathrm{pg} / \mathrm{mL}$ or as defined and reported by the source literature. ${ }^{12}$ All current assays for measuring PTH were included and all reports of elevated PTH within maintenance dialysis populations were assumed due to SHPT.

A 24-hour ABPM measurements of the participants were made with mobil-o-graph (I.E.M. GmbH, Stolberg, Germany) device, which can automatically measure blood pressure for 24 hours. The range of measurement is $70-260 \mathrm{mmHg}$ for systolic blood pressure, $45-180 \mathrm{mmHg}$ for diastolic blood pressure, and 40-240/minute for heart rate.

The 24-hour blood pressure measurements of the participants were measured between the individuals' hemodialysis session discharge and the next day. ${ }^{13,14}$ All patients informed about the 24-hour ambulatory BP monitoring and mobil-o-graph device by the researcher. They were also advised to avoid excessive activity and to keep their arms at heart level during the BP measurements. All patients were asked to record their bed-time and get-up-time. The definitions of 'day-time' and 'night-time' periods were based on the participants' own declaration. Using the hourly averages of ABPM recordings, day-time, night-time, and 24-hour averages of SBP, DBP, and mean BP were computed forevery patients. Day-time blood pressuremeasurements (08.00-24.00) were performed at 15-minute intervals, and night-time blood pressure measurements (24.00-08.00) were performed at 30-minute intervals. The device automatically measured and recorded the average of day and night, systolic and diastolic blood pressure, separately according to 
bed-time and get-up-time. Again, according to the sleep and wakefulness hours of the participants, the average pulse rate and pulse pressure were automatically measured by the device in two separate categories as day and night. Recordings were accepted, if more than $80 \%$ of the raw data were valid. Participants with incomplete or invalid ABPM were asked to repeat this procedure three days later. Participants who could not comply with ABPM for the second time, were excluded from the study. Valid ABPM was obtained in 70 patients in the first application, and 15 patients in the second application. A total of 15 patients (7 patients for invalid ABPM and 8 patients did not meet the study criteria) were not included in the study.

Statistical analysis of the data was performed using IBM SPSS version 22 statistical package programme. Shapiro-Wilk test was used to determine whether the data showed normal distribution. Descriptive data were given as mean \pm SD for continuous variables with normal distribution, median (quartile 1quartile 3) for continuous data with non-normal distribution, and number ( $\mathrm{n}$ ) and percentage (\%) for categorical variables. In comparison of two independent groups, Student-t test was used for normal distributed continuous data, Mann-Whitney U-test for non-normal distributed continuous data. Pearson Chisquare test was used to analyse categorical data. In order to determine the effect of independent variables on dependent variable, the binary logistic regression model with backward stepwise were used. Pearson's or Spearman correlation coefficient was used to evaluate the relationship between the two continuous data conforming to normal distribution. Significancelevel was $p<0.05$.

\section{RESULTS}

A total of 85 hemodialysis patients were included in the study. The mean age was $57.07 \pm 14.46$ years and $67.1 \%(n=57)$ were males. The sHPT rate was $58.8 \%(n=50)$, and non-dipper blood pressure phenomenon rate was $64.7 \%(n=55)$. Non-dipper blood pressure fenomene significantly higher in patients with sHPT than patients without sHPT $(p<0.001)$. The mean day-time systolic blood pressure $(p=0.020)$, mean night-time systolic blood pressure ( $p=0.001$ ), mean day-time diastolic blood pressure $(p=0.033)$ and mean night-time diastolic blood pressure ( $p=0.001$ ) were higher in patients with secondary hyperparathyroidism than without secondary hyperparathyroidism (Tablel).

Secondary hyperparathyroidism $(p=0.003)$ was an independent risk factor affecting circadian blood pressure (odds ratio [OR] 0.065, 95\% Cl: 0.11-0.390). Gender, ferritin, and blood urea nitrogen (BUN) levels were independently associated with non-dipperblood pressure phenomenon (Table II).

A moderately significant positive correlation was found between night-time blood pressure decrease and parathyroid hormone level $(r=0.346, p<0.001)$. There was a positive correlation between blood pressure change and K ( $p=0.004)$, urea ( $p$ $<0.001)$ and uric acid (0.042), and a negative correlation with ferritin ( $p=0.011$ ) level (Table III).
Table I: Demographic, blood pressure and circadian blood pressure rhythm characteristics of the participants.

\begin{tabular}{|c|c|c|c|c|}
\hline & $\begin{array}{c}\text { sHPT } \\
\text { No } \\
(n=35) \\
n(\%)\end{array}$ & $\begin{array}{c}\text { SHPT } \\
\text { Yes }(n=50) \\
n(\%)\end{array}$ & $\begin{array}{c}\text { Total }(n=85) \\
n(\%)\end{array}$ & p-value \\
\hline \multicolumn{5}{|l|}{ Gender } \\
\hline Male & $28(80.0)$ & $29(58.0)$ & $57(67.1)$ & \multirow{2}{*}{0.038} \\
\hline Female & $7(20.0)$ & $21(42.0)$ & $28(32.9)$ & \\
\hline \multicolumn{5}{|l|}{ Marital status } \\
\hline Married & $27(77.1)$ & $43(86.0)$ & $70(82.4)$ & \multirow{2}{*}{0.388} \\
\hline Single or widow & $8(22.9)$ & $7(14.0)$ & $15(17.6)$ & \\
\hline \multicolumn{5}{|l|}{ Education status } \\
\hline Under high school & $21(60.0)$ & $34(68.0)$ & $55(64.7)$ & \multirow[b]{2}{*}{0.494} \\
\hline $\begin{array}{l}\text { High school and } \\
\text { above }\end{array}$ & $14(40.0)$ & $16(32.0)$ & $30(35.3)$ & \\
\hline \multicolumn{5}{|l|}{ Income level } \\
\hline Low & $11(31.4)$ & $26(52.0)$ & 37 (43.5) & \multirow{3}{*}{0.077} \\
\hline Medium & $24(68.6)$ & $24(48.0)$ & $48(56.5)$ & \\
\hline Good & 0 & 0 & 0 & \\
\hline \multicolumn{5}{|l|}{ Hypertension status } \\
\hline Have not & $11(31.4)$ & $15(30.0)$ & $26(30.6)$ & \multirow{2}{*}{0.537} \\
\hline Have & $24(68.6)$ & $35(70.0)$ & $59(69.4)$ & \\
\hline \multicolumn{5}{|c|}{ Diabetes Mellitus status } \\
\hline Have not & 27 (77.1) & $30(60.0)$ & $57(67.1)$ & \multirow{2}{*}{0.077} \\
\hline Have & $8(22.9)$ & $20(40.0)$ & $28(32.9)$ & \\
\hline \multicolumn{5}{|c|}{ Coronary artery disease status } \\
\hline Have not & $25(71.4)$ & $36(72.0)$ & $61(71.8)$ & \multirow{2}{*}{0.572} \\
\hline Have & $10(28.6)$ & $14(28.0)$ & $24(28.2)$ & \\
\hline \multicolumn{5}{|l|}{ Smoking } \\
\hline No & $32(91.4)$ & $41(82.0)$ & $73(85.9)$ & \multirow{2}{*}{0.182} \\
\hline Yes & $3(8.6)$ & $9(18.0)$ & $12(14.1)$ & \\
\hline \multicolumn{5}{|l|}{ Alcohol } \\
\hline No & 34 (97.1) & $49(98.0)$ & $83(97.6)$ & \multirow{2}{*}{0.657} \\
\hline Yes & $1(2.9)$ & $1(2.0)$ & $2(2.4)$ & \\
\hline \multicolumn{5}{|c|}{ Circadian blood pressure } \\
\hline Dipper & $22(62.9)$ & $8(16.0)$ & $30(35.3)$ & \multirow{2}{*}{$<0.001$} \\
\hline \multirow[t]{2}{*}{ Non-dipper } & $13(31.7)$ & $42(84.0)$ & $55(64.7)$ & \\
\hline & & $\begin{array}{c}\text { SHPT } \\
\text { No }\end{array}$ & $\begin{array}{l}\text { SHPT } \\
\text { Yes }\end{array}$ & p-value \\
\hline \multicolumn{2}{|l|}{ Age (year) } & $57.66 \pm 15.73$ & $56.66 \pm 15.42$ & 0.772 \\
\hline \multicolumn{2}{|c|}{ Hemodialysis vintage (year) } & $2.00(1.75-4.00)$ & $3.00(2.00-8.00)$ & 0.119 \\
\hline $\begin{array}{l}\text { Hypertension vinta } \\
\text { (year) }\end{array}$ & $(n=59)$ & $\begin{array}{c}6.00 \\
(0.00-10.00) \\
\end{array}$ & $\begin{array}{c}5.00 \\
(0.00-15.00) \\
\end{array}$ & 0.487 \\
\hline Parathormone (pg/ & & $\begin{array}{c}162.40 \\
(112.60-260.90)\end{array}$ & $\begin{array}{c}524.90 \\
(411.30-724.25) \\
\end{array}$ & $<0.001$ \\
\hline BMI $\left(\mathrm{kg} / \mathrm{m}^{2}\right)$ & & $23.57 \pm 4.34$ & $24.36 \pm 4.88$ & 0.440 \\
\hline $\begin{array}{l}\text { Mean arterial press } \\
(\mathrm{mmHg})\end{array}$ & e (MAP) & $103.97 \pm 17.36$ & $104.12 \pm 19.31$ & 0.971 \\
\hline $\begin{array}{l}\text { Mean systolic blooc } \\
\text { ( } 24 \text { hours) ( } \mathrm{mmHg} \text { ) }\end{array}$ & oressure & $130.29 \pm 21.89$ & $131.36 \pm 26.69$ & 0.845 \\
\hline $\begin{array}{l}\text { Mean systolic bloo } \\
\text { (daytime) }(\mathrm{mmHg})\end{array}$ & oressure & $122.80 \pm 19.15$ & $136.34 \pm 29.73$ & 0.020 \\
\hline $\begin{array}{l}\text { Mean systolic blooc } \\
\text { (night) (mmHg) }\end{array}$ & ressure & $121.03 \pm 18.54$ & $141.92 \pm 32.95$ & 0.001 \\
\hline $\begin{array}{l}\text { Mean diastolic bloo } \\
\text { ( } 24 \text { hours) ( } \mathrm{mmHg} \text { ) }\end{array}$ & pressure & $81.66 \pm 14.18$ & $81.02 \pm 15.66$ & 0.848 \\
\hline $\begin{array}{l}\text { Mean diastolic bloo } \\
\text { (daytime) }(\mathrm{mmHg})\end{array}$ & pressure & $79.46 \pm 13.01$ & $87.04 \pm 17.56$ & 0.033 \\
\hline $\begin{array}{l}\text { Mean diastolic bloo } \\
\text { (night) }(\mathrm{mmHg})\end{array}$ & pressure & $76.00 \pm 12.77$ & $88.68 \pm 18.69$ & 0.001 \\
\hline $\begin{array}{l}\text { Mean pulse pressu } \\
\text { hours) }\end{array}$ & & $\begin{array}{c}49.00 \\
(42.0-54.0)\end{array}$ & $\begin{array}{c}42.50 \\
(36.7-63.5)\end{array}$ & 0.678 \\
\hline Mean pulse pressu & (daytime) & $\begin{array}{c}50.00 \\
(40.0-53.0) \\
\end{array}$ & $\begin{array}{c}44.00 \\
(35.7-64.0) \\
\end{array}$ & 0.649 \\
\hline Mean pulse pressu & (night) & $\begin{array}{c}50.00 \\
(42.0-56.0)\end{array}$ & $\begin{array}{c}45.00 \\
(38.0-62.0)\end{array}$ & 0.823 \\
\hline
\end{tabular}


Table II: Binary logistic regression model for relationship between circadian rhythm and sociodemographic characteristics.

\begin{tabular}{|c|c|c|c|}
\hline Variables & $\begin{array}{l}\text { Odds } \\
\text { Ratios }\end{array}$ & $\begin{array}{c}\text { Confidence } \\
\text { Interval } \\
(95.0 \%) \\
\end{array}$ & p-value \\
\hline \multicolumn{4}{|l|}{ Gender } \\
\hline Female & ref & & \multirow{2}{*}{0.043} \\
\hline Male & 0.107 & $0.012-0.936$ & \\
\hline \multicolumn{4}{|l|}{ Income level } \\
\hline Insufficient & ref & & \multirow{2}{*}{0.245} \\
\hline Sufficient & 3.36 & $0.435-25.955$ & \\
\hline \multicolumn{4}{|l|}{ Hypertension status } \\
\hline Have not & ref & & \multirow{2}{*}{0.868} \\
\hline Have & 0.84 & $0.113-6.305$ & \\
\hline \multicolumn{4}{|c|}{ Diabetes Mellitus status } \\
\hline Have not & ref & & \multirow{2}{*}{0.077} \\
\hline Have & 8.44 & $0.793-89.920$ & \\
\hline \multicolumn{4}{|c|}{ Coronary artery disease status } \\
\hline Have not & Ref & & \multirow{2}{*}{0.177} \\
\hline Have & 0.28 & $0.043-1.784$ & \\
\hline \multicolumn{4}{|l|}{ Smoking } \\
\hline No & Ref & & \multirow{2}{*}{0.583} \\
\hline Yes & 0.58 & $0.161-25.644$ & \\
\hline \multicolumn{4}{|l|}{ Alcohol } \\
\hline No & Ref & & \multirow{2}{*}{0.378} \\
\hline Yes & 0.09 & $0.000-19.346$ & \\
\hline \multicolumn{4}{|c|}{ Secondary hyperparathyroidism } \\
\hline Have not & Ref & & \\
\hline Have & 0.07 & $0.011-0.390$ & 0.003 \\
\hline Age & 0.99 & $0.936-1.063$ & 0.940 \\
\hline NLR & 0.31 & $0.779-2.221$ & 0.306 \\
\hline BMI $\left(\mathrm{kg} / \mathrm{m}^{2}\right)$ & 1.04 & $0.834-1.296$ & 0.729 \\
\hline Ferritin (ng/ml) & 1.00 & $1.001-1.006$ & 0.007 \\
\hline Phosphate (mg/dl) & 0.48 & $0.216-1.083$ & 0.077 \\
\hline BUN (mg/dl) & 0.94 & $0.890-0.908$ & 0.016 \\
\hline Creatinine (mg/dl) & 1.87 & $0.944-3.719$ & 0.072 \\
\hline Uric acid (mg/dl) & 1.78 & $0.680-4.647$ & 0.241 \\
\hline Total protein (g/dl) & 0.94 & $0.160-5.490$ & 0.943 \\
\hline Albumin (g/dl) & 1.62 & $0.115-22.959$ & 0.720 \\
\hline $\begin{array}{l}\text { NLR: Neutrophil to } \\
\text { nitrogen, CRP: C-re } \\
R^{2}=0.625, \text { model } p \\
\end{array}$ & $\begin{array}{l}\text { ody mas } \\
\text { alcium }\end{array}$ & $\begin{array}{l}\text { index, BUN: Bloc } \\
\text { hosphate (Nage }\end{array}$ & $\begin{array}{l}\text { d urea } \\
\text { rerke }\end{array}$ \\
\hline
\end{tabular}

Table III: Correlation between the fall in blood pressure and continuous variables.

\begin{tabular}{|l|l|l|}
\hline Variables & $\mathbf{r}$ & $\mathbf{p}$ \\
\hline Parathormone (pg/ml) & 0.346 & $\mathbf{0 . 0 0 1}$ \\
\hline $\mathrm{Na}(\mathrm{meq} / \mathrm{L})$ & -0.115 & 0.296 \\
\hline $\mathrm{K}(\mathrm{meq} / \mathrm{L})$ & 0.313 & $\mathbf{0 . 0 0 4}$ \\
\hline Ca $(\mathrm{mg} / \mathrm{dl})$ & -0.022 & 0.844 \\
\hline Phosphate (mg/dl) & 0.199 & 0.067 \\
\hline Ferritin (ng/ml) & -0.274 & $\mathbf{0 . 0 1 1}$ \\
\hline CRP (mg/L) & 0.011 & 0.918 \\
\hline Mean heart rate & -0.023 & 0.837 \\
\hline BMI (kg/m²) & -0.004 & 0.971 \\
\hline NLR & 0.020 & 0.855 \\
\hline Age (year) & 0.065 & 0.554 \\
\hline Hemodialysis vintage (year) & -0.004 & 0.971 \\
\hline BUN (mg/dl) & 0.448 & $<\mathbf{0 . 0 0 1}$ \\
\hline Creatinine (mg/dl) & 0.027 & 0.804 \\
\hline Uric acid (mg/dl) & 0.222 & $\mathbf{0 . 0 4 2}$ \\
\hline Total cholestrole (mg/dl) & -0.211 & 0.052 \\
\hline Triglyseride (mg/dl) & -0.084 & 0.444 \\
\hline HDL (mg/dl) & -0.062 & 0.570 \\
\hline LDL (mg/dl) & -0.174 & 0.112 \\
\hline Ca* P & 0.160 & 0.143 \\
\hline $\begin{array}{l}\text { NLR: Neutrophil to leukocyte ratio, BMl: Body mass index, BUN: Blood urea } \\
\text { nitrogen, CRP: C-reactive protein, Ca*P: Calcium * Phosphate. }\end{array}$ \\
\hline
\end{tabular}

DISCUSSION
To the best of authors' knowledge, this current study is the first study in the literature to investigate the relationship between secondary hyperparathyroidism and circadian rhythm, which is common in hemodialysis patients. In this study, sHPT and nondipper blood pressure phenomenon is common among hemodialysis patients. The current study showed that SHPT is related with circadian blood pressure and it increased the non-dipper blood pressure phenomenon rate.

The current study has found that mean arterial blood pressure, mean systolic and diastolic blood pressures (day-time and night-time) were higher in patients with secondary hyperparathyroidism. A possible relationship between sHPT and hypertension has been widely reported in the literature and various pathogenetic mechanisms have been described. ${ }^{15,16}$ Previous studies have showed a significant decrease in blood pressure after parathyroidectomy. ${ }^{17,18}$ The data the present authors obtained regarding the relationship between hyperparathyroidism and high blood pressure were similar to the literature data. Thus, the authors believe that hypertension and high blood pressure, which are an important cause of mortality and morbidity in hemodialysis patients, can be controlled by treating high parathyroid hormone levels.

Wang et al. reported that the reverse dipper blood pressure pattern is closely related to severe kidney damage and cardiovascular events in patients with chronic renal failure, thus these patients should be given special attention. ${ }^{19}$ The current study has found that non-dipper blood pressure pattern was more common in hemodialysis patients, who developed secondary hyperparathyroidism. The current study showed that secondary hyperparathyroidism that develops in hemodialysis patients increases the non-dipper blood pressure pattern. Luigi et al. reported that the non-dipper blood pressure pattern seen at a frequency of $57 \%$ regressed to $38 \%$ after the treatment of primary hyperparathyroidism. ${ }^{11}$ In this study, when the relationship between parathyroid hormone and circadian rhythm was examined, it was found that parathyroid hormone levels were higher in the group with non-dipper phenomenon, and there was also a correlation between the percentage of change between day and night blood pressures and parathyroid hormone levels. Many previous studies reported that parathyroid hormone had an effect on blood pressure and increased blood pressure..$^{20-22}$ Additionally, some studies were reported that parathyroid hormone levels were higher in patients with non-dipper patterns. ${ }^{19,23}$ In this context, the findings of the authors that parathyroid hormone levels are high in the group with non-dipper pattern is supported by literature data. Significant correlation between day and night blood pressure change rate of parathyroid hormone level supported the effect of secondary hyperparathyroidism on circadian rhythm. Wang et al. reported in their study that participants with non-dipper pattern blood pressure had higher parathyroid hormone levels. ${ }^{23}$ The common belief in the literature is that controlling the parathyroid hormone level is important in normal blood pressure. The findings are consistent with the literature data. Based on the findings the present authors obtained, it was thought 
that controlling the parathyroid hormone level could prevent the deterioration of the circadian rhythm, which is an important cardiovascular risk factor, in addition to controlling blood pressure.

The first limitation of this study is that it is cross-sectional and single-centre study. The small sample size is another important limitation of this study, but the fact is that hemodialysis patients constituted the study population resulted in a small sample size. The 24-hour blood pressure measurement of all participants was performed once, so fluctuations in blood pressure at different times could not be evaluated. Although there was no statistically significant difference between socio-demographic characteristics of the groups with dipper and non-dipper patterns, all factors that could affect circadian rhythm could not be excluded.

Despite all these limitations, this study is the first study investigating the relationship between secondary hyperparathyroidism and circadian rhythm, and contributes to the literature. In future studies, the relationship between sHPT and circadian rhythm should beexamined inlargerpopulations, and by considering the factors that affect the circadian rhythm.

\section{CONCLUSION}

High parathyroid hormone levels seen in SHPT are associated with an increase in both systolic and diastolic blood pressures, and an increase in the non-dipper blood pressure pattern by reducing the decrease in the night blood pressure that is the normal circadian rhythm. Treatment of secondary hyperparathyroidism is important in the control of blood pressure and normal circadian rhythm in tertiary protection in hemodialysis patients.

\section{FUNDING:}

Fırat University Scientific Research Projects Coordination Unit provided financial support for this study with project No. TF-2019/19-13.

\section{ETHICAL APPROVAL:}

The study protocol was approved by the Ethics Committee of Firat University (No. 15-17, Date: 17/10/2019). The study was conducted in accordance with the principles of the Declaration of Helsinki.

\section{PATIENTS' CONSENT:}

Written informed consents were obtained from all patients.

\section{CONFLICT OF INTEREST:}

The authors declared no conflict of interest.

\section{AUTHORS' CONTRIBUTION:}

BY: Data collection, design, compiling, and discussion, led and conceived the project, and authored the manuscript.

EO: Collecting and analysing data and discussion.

EP: Collecting data and discussion.

MOK: Collecting statistics and analysing data.

MD: Design, data collection, and discussion
1. O'Brien E, Parati G, Stergiou G, Asmar R, Beilin L, Bilo G, et al. European society of hypertension working group on blood pressure monitoring. J Hypertens 2013; 31(9): 1731-68. doi.org/10.1097/hjh.0b013e328363e964.

2. Salles GF, Reboldi G, Fagard RH, Cardoso CR, Pierdomenico $\mathrm{SD}$, Verdecchia $\mathrm{P}$, et al. Prognostic effect of the nocturnal blood pressure fall in hypertensive patients: The ambulatory blood pressure collaboration in patients with hypertension (ABC-H) meta-analysis. Hypertension 2016; 67(4):693-700. doi.org/10.1161/hypertensionaha.115. 06981.

3. O'Brien E, Sheridan J, O'Malley K. Dippers and non-dippers. Lancet 1988; 2:397. http://doi.org/10.1016/S0140-6736 (88)92867-X.

4. Roush GC, Fagard RH, Salles GF, Pierdomenico SD, Reboldi $G$, Verdecchia $P$, et al. Prognostic impact from clinic, daytime, and night-time systolic blood pressure in nine cohorts of 13,844 patients with hypertension. J Hypertens 2014; 32(12):2332-40. doi.org/10.1097/hjh.0000000000 000355.

5. Fagard RH, Thijs L, Staessen JA, Clement DL, De Buyzere $M L$, De Bacquer DA. Night-day blood pressure ratio and dipping pattern as predictors of death and cardiovascular events in hypertension. J Hum Hypertens 2009; 23(10): 645-53. doi.org/10.1038/jhh.2009.9.

6. Major RW, Cheng MRI, Grant RA, Shantikumar S, Xu G, Oozeerally I, et al. Cardiovascular disease risk factors in chronic kidney disease: A systematic review and metaanalysis. PLoS One 2018; 13(3):e0192895. dx.doi.org/ 10.1371\%2Fjournal. pone.0192895.

7. Pogue V, Rahman M, Lipkowitz M, Toto R, Miller E, Faulkner $M$, et al. African American study of kidney disease and hypertension collaborative research group. Disparate estimates of hypertension control from ambulatory and clinic blood pressure measurements in hypertensive kidney disease. Hypertension 2009; 53(1):20-7. doi.org/10.1161/ hypertensionaha.108.115154.

8. Ettehad D, Emdin CA, Kiran A, Anderson SG, Callender T, Emberson J, et al. Blood pressure lowering for prevention of cardiovascular disease and death: A systematic review and meta-analysis. Lancet 2016; 387(10022):957-967. doi.org/ 10.1016/s0140-6736(15)01225-8.

9. Wang C, Ye Y, Liu C, Zhou Y, Lv L, Cheng C, et al. Evening versus morning dosing regimen drug therapy for chronic kidney disease patients with hypertension in blood pressure patterns: A systematic review and meta-analysis. Intern Med J 2017; 47(8):900-906. doi.org/10.1111/imj. 13490.

10. Piovesan A, Molineri N, Casasso F, Emmolo I, Ugliengo G, Cesario $F$, et al. Left ventricular hypertrophy in primary hyperparathyroidism. Effects of successful parathyroidectomy. Clin Endocrinol (Oxf) 1999; 50(3):321-8. doi.org/10.1046/j.1365-2265.1999.00651.x.

11. Luigi P, Chiara FM, Laura Z, Cristiano M, Giuseppina C, Luciano $C$, et al. Arterial hypertension, metabolic syndrome and subclinical cardiovascular organ damage in patients with asymptomatic primary hyperparathyroidism before and after parathyroidectomy: preliminary results. Int J Endocrinol 2012; 2012:408295. http://doi.org/10.1155/ 
2012/408295.

12. National Kidney Foundation. K/DOQI clinical practice guidelines for bone metabolism and disease in chronic kidney disease. Am J Kidney Dis 2003; 42(4 Suppl 3): S1-201.

13. Weiss W, Gohlisch C, Harsch-Gladisch C, Tölle M, Zidek W, van der Giet M. Oscillometric estimation of central blood pressure: Validation of the mobil-O-graph in comparison with the sphygmoCor device. Blood Press Monit 2012; 17(3):128-31. doi.org/10.1097/mbp.0b013e328353ff63.

14. Wei W, Tölle M, Zidek W, Van der Giet M. Validation of the mobil-O-Graph: 24 h-blood pressure measurement device. Blood pressure monitoring 2010; 15(4):225-28. http:// doi.org/10.1097/mbp.0b013e328338892f.

15. Stern A, Sachdeva S, Kapoor R, Singh J, Sachdeva S. High blood pressure in dialysis patients: cause, pathophysiology, influence on morbidity, mortality and management. J Clin Diagn Res 2014; 8(6):ME01-4. http://dx.doi.org/ $10.7860 \% 2 F J C D R \%$ 2F2014\%2F8253.4471.

16. Massry SG, Iseki K, Campese VM. Serum calcium, parathyroid hormone, and blood pressure. Am J Nephrol 1986; 6(Suppl 1):19-28.

17. Goldsmith DJ, Covic AA, Venning MC, Ackrill P. Blood pressure reduction after parathyroidectomy for secondary hyperparathyroidism: further evidence implicating calcium homeostasis in blood pressure regulation. Am J Kidney Dis 1996; 27(6):819-825.
18. Sofronie AC, Kooij I, Bursot C, Santagati G, Coindre JP, Piccoli GB. Full normalisation of severe hypertension after parathryoidectomy - a case report and systematic review. BMC Nephrol 2018; 19:112. doi.org/10.1186/s12882018-0900-y.

19. Wang C, Zhang J, Liu X, Ye Z, Peng H, Chen Z, et al. Reversed dipper blood-pressure pattern is closely related to severe renal and cardiovascular damage in patients with chronic kidney disease. PLoS One 2013; 8(2):e55419. doi.org/10.1371/journal.pone.0055419.

20. Heyliger A, Tangpricha V, Weber C, Sharma J. Parathyroidectomy decreases systolic and diastolic blood pressure in hypertensive patients with primary hyperparathyroidism. Surgery 2009; 146(6):1042-47. dx.doi.org/10.1016\%2Fj.surg.2009.09.024.

21. Simeoni M, Perna AF, Fuiano G. Secondary Hyperparathyroidism and Hypertension: An Intriguing Couple. J Clin Med 2020; 9(3):629. doi.org/10.3390/ jcm9030629.

22. Schiffl H, Lang SM. Hypertension Secondary to PHPT: Cause or Coincidence?. Int J Endocrinol 2011; 2011:974647. doi.org/10.1155/2011/974647.

23. Wang C, Ye Z, Li Y, Zhang J, Zhang Q, Ma X, et al. Prognostic value of reverse dipper blood pressure pattern in chronic kidney disease patients not undergoing dialysis: Prospective cohort study. Sci Rep 2016; 6:34932. doi.org/ 10.1038\%2Fsrep34932. 